\title{
Effects of leaf response velocity on spray deposition with an air-assisted orchard sprayer
}

\author{
Jun $\mathrm{Li}^{1,2}$, Zhiqiang $\mathrm{Li}^{1}$, Yakun $\mathrm{Ma}^{1}$, Huajun $\mathrm{Cui}^{1}$, Zhou Yang ${ }^{1,3}$, Huazhong $\mathrm{Lu}^{1,4^{*}}$ \\ (1. College of Engineering, South China Agricultural University, Guangzhou 510642, China; \\ 2. Key Laboratory of Key Technology on Agricultural Machine and Equipment, Ministry of Education, \\ South China Agricultural University, Guangzhou 510642, China; \\ 3. Jiaying University, Meizhou 514015, Guangdong, China; \\ 4. Guangdong Academy of Agricultural Sciences, Guangzhou 510640, China)
}

\begin{abstract}
The interaction between leaves and airflow has a direct effect on the droplet deposition characteristics of the leaf canopy. In order to make clear the mechanism of droplet deposition in terms of the interaction between the droplets and leaves from the point of the leaf aerodynamic response velocity, the leaf movement under different airflow velocities and the influence of the leaf aerodynamic response on droplet coverage ratio were investigated. The effect of the aerodynamic response velocity of a leaf on the droplet deposition of the leaf surface was investigated. The aerodynamic characteristics of the leaf were analyzed theoretically. Boundary layer theory from fluid mechanics was used to develop a model of the leaf aerodynamic response velocity to nonperiodic excitations based on a convolution integral method. Target leaf aerodynamic velocities were detected using a high-speed camera, and the results indicated that the modeled leaf aerodynamic response velocity matched the measured values. At given conditions of spray liquid and leaf surface texture, the spray test showed that the droplet coverage ratio was influenced by the leaf aerodynamic response velocity, the droplet coverage ratio increased and then decreased with the leaf response velocity. Through analyze four droplets deposition state, the highest droplet deposition ratio and best deposition state on the leaf surface occur when the leaf aerodynamic response velocity was less than $0.14 \mathrm{~m} / \mathrm{s}$. According to the analysis of droplet deposition states, the uniformity of the droplet size and quantity distribution of droplets on the leaf surface related to the leaf aerodynamic response velocity. The results can provide a basis for the design and optimization of orchard air sprayers.
\end{abstract}

Keywords: air-assisted spray, leaf wind vibration, leaf aerodynamic response velocity, droplet deposition states, droplet retention, orchard

DOI: $10.25165 /$ j.ijabe.20211401.5435

Citation: Li J, Li Z Q, Ma Y K, Cui H J, Yang Z, Lu H Z. Effects of leaf response velocity on spray deposition with an air-assisted orchard sprayer. Int J Agric \& Biol Eng, 2021; 14(1): 123-132.

\section{Introduction}

The application of pesticides is an indispensable preventative measure that helps prevent yield losses due to organisms and pests that are harmful to crops ${ }^{[1,2]}$. Pesticides are applied mostly in the orchard with air-assisted sprayers, in which spray generated by a fan carries pesticide droplets to the target canopy. The forced air-jet transports the spray droplets to the target, moving and lifting the leaves to allow penetration and depositing the droplets on the plant surface, including the underside of the leaves ${ }^{[3]}$.

The pesticide utilization efficiency is influenced by many factors, and the final amount of pesticide deposited inside a target tree canopy is influenced by the physical properties of the spray, sprayer design and settings, spray operation parameters, orchard characteristics, and weather conditions ${ }^{[4,5]}$. The spray application

Received date: 2019-09-12 Accepted date: 2020-06-22

Biographies: Jun Li, PhD, Professor, research interest: agricultural automation and intelligence, Email: autojunli@scau.edu.cn; Zhiqiang Li, Master candidate, research interest: air-assisted spraying, Email: 1130080330@qq.com; Yakun Ma, Master candidate, research interest: air-assisted spraying,Email: yakunma@ stu.scau.edu.cn; Huajun Cui, Master candidate, research interest: air-assisted spraying, Email: 425911292@qq.com; Zhou Yang, PhD, Professor, research interest: agricultural mechanization engineering, Email: yangzhou@scau.edu.cn. *Corresponding author: Huazhong Lu, PhD, Professor, research interest: agricultural mechanization management. College of Engineering, South China Agricultural University, Guangzhou 510642, China. Tel: +86-13808870688, Email: huazlu@scau.edu.cn. and efficacy of leaf pesticides depend on four processes of the active ingredients in the applied formulation: deposition, retention, uptake and translocation ${ }^{[6,7]}$. The spray deposition and droplet retention on the leaf surface determine the pesticide utilization efficiency. The bearing capacity of the leaf surface for droplets is especially important for droplet deposition ${ }^{[8]}$. There is a critical volume of liquid that can be carried by crop leaves, which is called the first-order loss point; there is an automatic loss of fluid when the liquid volume exceeds this value. After this loss, the liquid reaches maximum stable retention on the leaf surface ${ }^{[9]}$. Liquid retention and loss on the leaf surface are associated with the spray method, droplet diameter and spray solution characteristics. The use of a coarse-droplet spray results in a greater loss than that with a fine-droplet spray ${ }^{[4]}$. Many studies have shown that reduced surface tension of the liquid can increase the loss of the liquid and reduce the liquid deposition on the leaf surface. Retention of spray by a leaf can also be affected by plant characteristics, such as plant and leaf size ${ }^{[6][7]}$ and the wettability of the leaf surfaces ${ }^{[10]}$.

The spray operation parameters are the spraying distance, spray droplet diameter, spray volume and airflow rate ${ }^{[11]}$. The factors that affect the droplet coverage on the leaf surface are interconnected, and changes in one factor can affect other factors. Thus, the spray parameters influence droplet coverage ${ }^{[12]}$. The droplet diameter and droplet velocity have significant influences on droplet deposition ${ }^{[13]}$. Compared with larger droplets, smaller ones can spread relatively further on the leaf surface and remain 
relatively longer, thus allowing the active pesticide to penetrate into the leaf tissue more effectively ${ }^{[14,15]}$. However, small-diameter droplets are more susceptible to drift and evaporation ${ }^{[16]}$. Air-assisted spraying can improve droplet deposition on a canopy and affect the spray droplet diameter ${ }^{[17]}$, potentially causing spray droplets to drift ${ }^{[18]}$. The spray retention of pesticide droplets is closely related to the leaf inclination angle, and adhering droplets on a leaf with a low inclination angle can reduce translocation and loss and aid in the retention of the spray liquid on the leaf ${ }^{[19]}$. Under spray application with normal operational parameters, the target leaf vibrates under the action of airflow, and the interaction between the dynamic leaf and droplets will directly affect droplet deposition and the final retention of the spray on the leaf surface ${ }^{[20]}$. At present, most research articles about the interaction mechanism between droplets and leaves have been based on a static target leaf, and the influence of the spray operational parameters on droplet coverage has rarely been studied in terms of the dynamic interaction between leaves and spray droplets.

The leaves are the main organ in the canopy of the plant, and the leaves on the canopy are the main objects of bearing or action of airflow and spray deposition. Issues related to the canopy, including wind and sand fixation, intercepting rainwater and orchard spray, are the main research objects. Many studies regarding fluid-solid coupling with objects such as leaves and tree canopy have been performed domestically and abroad, and the coupling mechanism has been explored ${ }^{[21]}$. The spatial position of the leaf under the action of airflow will change in real-time, and the response velocity and shape of the leaf will change. Vogel pointed out that the resistance coefficient of the leaves is much greater than that of a rigid body of the same shape, and its size is directly related to the leaf area ${ }^{[22]}$. The leaf, as the most important component of the canopy, occupies $80 \%$ of the canopy and serves as the main air-bearing object ${ }^{[23]}$. Petroff et al. ${ }^{[24]}$ studied the particle sedimentation characteristics of a broad-leaved canopy under different wind velocities, pointing out that canopy size, leaf shape and inclination angle are important factors that influence particulate matter deposition. In summary, many studies on droplet-leaf interaction are based on static target leaves, and research on dynamic target leaves and spray droplet interactions is rare. However, in the air-assisted sprayer operation, the existence of the disturbance caused by airflow rate on the leaves will inevitably affect the final deposition state of droplets on them. Thus, the study of the deposition characteristics of droplets on dynamic leaves warrants further examination.

The process of spray retention is strongly influenced by the physical and chemical properties of the spray liquid, leaf surface texture and spray operation parameters such as spray distance, outlet airflow velocity and droplet diameter. Many researchers have conducted extensive research into the effects of the operation factors, but few of them pay enough attention to the mechanism of spray retention in terms of the droplet-leaf interaction. In this paper, to explain how the interaction affects the droplet deposition on the leaf at given conditions of spray liquid and leaf surface texture, the leaf aerodynamic response velocity (obtained by dividing the distance from the top to bottom dead center of leaf vibration by the time taken during the vibration process of the leaf under the influence of airflow) was introduced. The characteristics of the interaction between dynamic target leaves and droplets with an orchard air-assisted sprayer were studied from the perspective of biological systems engineering. The aerodynamics of the target leaf under airflow was analyzed. The boundary layer theory from fluid mechanics was used to develop a model of the leaf aerodynamic response velocity to nonperiodic excitations based on a convolution integral method. A spray test of the target leaf was performed, and a high-speed camera was used to measure the droplet deposition process. The aerodynamic response velocity of the leaf, the leaf vibration angle and droplet coverage were measured. The aerodynamic response velocity model of the leaf was verified via experimental data, and the wind vibration angle of the leaf was analyzed. The aerodynamic response velocity of the leaf, its corresponding droplet coverage, and the effect on the dynamic target leaf were explored. The characteristics of droplet deposition on the leaf surface and the control effect were comprehensively analyzed to provide a reference for correlation research of orchard spray.

\section{Materials and methods}

\subsection{Model of leaf aerodynamic response}

In the process of an actual fluid passing through an object, the force acting on this object is not only the normal pressure but also the tangential force caused by the viscosity of the fluid, namely the frictional resistance. The drag force is due to the combined effects of the pressure and wall shear forces in the flow direction, and the lift force is the component in the direction normal to the page that tends to move the body ${ }^{[25]}$, as shown in Figure 1.
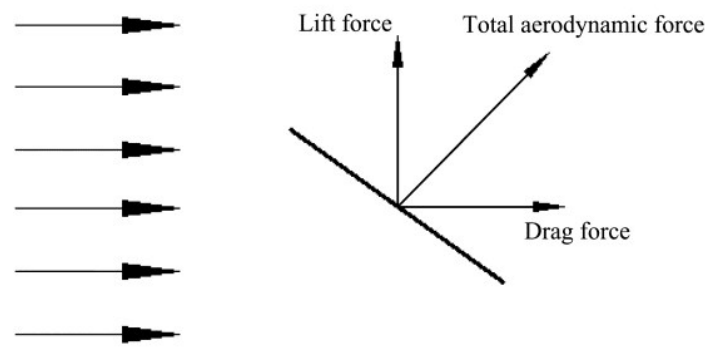

Figure 1 Lift force and drag force

2.1.1 Drag force on leaf

The drag force acting on the leaf is given by

$$
F_{D}=C_{D} \frac{\rho_{a} v_{a}^{2}}{2} A_{F}
$$

where, $C_{D}$ is the drag coefficient; $v_{a}$ is the velocity of the airflow with respect to the leaf, $\mathrm{m} / \mathrm{s} ; \rho_{a}$ is the density of air $\left(\rho_{a}=\right.$ $1.293 \mathrm{~kg} / \mathrm{m}^{3}$ ); and $A_{F}$ is typically the frontal area (the area projected on a plane normal to the direction of flow).

The drag coefficient $C_{D}$ is a dimensionless quantity used to quantify the drag resistance of an object in a fluid environment. The drag coefficient is always associated with a particular surface; in general, CD depends on the Reynolds number ${ }^{[25]}$. The Reynolds number is defined as

$$
R e=\frac{v_{a} d}{v}
$$

where, $d$ is the width of the target leaf, m, the widths of litchi and citrus leaves are $0.04 \mathrm{~m}$ and $0.03 \mathrm{~m}$, respectively; $v$ is the kinematic viscosity of air $\left(\mathrm{m}^{2} / \mathrm{s}\right), v=16.6 \times 10^{-6} \mathrm{~m}^{2} / \mathrm{s}$.

In the following spray experiment, $v_{a}$ was set to $2.19 \mathrm{~m} / \mathrm{s}$, $2.57 \mathrm{~m} / \mathrm{s}, 2.8 \mathrm{~m} / \mathrm{s}$, and $3.07 \mathrm{~m} / \mathrm{s}$ (in response to fan frequencies of $35 \mathrm{~Hz}, 40 \mathrm{~Hz}, 45 \mathrm{~Hz}$, and $50 \mathrm{~Hz}$, respectively; the distance between the leaf and fan outlet is $1 \mathrm{~m}$ ). Substituting these parameter values into Equation (2), the range of $R e$ is from 5277 to 7398 . Combined with the relation curve of drag coefficients for flow around a circular disk, when $R \mathrm{e}>10^{3}, C_{D} \approx 1.2^{[26]}$

The leaf frontal area projected onto a plane normal to the 
airflow direction is $A_{F}=A_{L} \cdot \sin \alpha$, where $A_{L}$ is the leaf area and $\alpha$ is the leaf initial inclination angle (the angle between the leaf plane and the horizontal plane). The leaf is approximated as an ellipse with a major axis and minor axis. The ellipse area equation is $A_{L}=0.25 \pi a b$, where $a$ and $b$ are the length of the major axis and minor axis, respectively.

In the process of air-assisted spray application, the initial leaf inclination angle $\alpha_{0}\left(0^{\circ} \leq \alpha \leq 90^{\circ}\right)$ changes to $\alpha$. If $\alpha_{0}<\alpha \leq 90^{\circ}$, the actual value of the leaf frontal area is greater than the calculated value. If $\alpha_{0}<\alpha \leq 180^{\circ}$, combined with $A_{F}=A_{L} \cdot \sin \alpha$, the actual value of the leaf frontal area can increase first and then decrease with the increasing of leaf inclination angle $\alpha$, and the actual value of $A_{F}$ is maximized at $\alpha=90^{\circ}$. According to observations from the test of the leaf aerodynamic response, the correction angle $\beta$ is added based on the initial inclination angle $\alpha_{0}$ to obtain a value closer to the actual $\left.A_{F}, \beta=10 v_{a},{ }^{\circ}\right)$.

Hence, the drag force acting on the leaf is given by

$$
F_{D}=0.61 v_{a}^{2} a b \sin (\alpha+\beta)
$$

\subsubsection{Lift force on the leaf}

The lift force acting on the leaf is given by

$$
F_{L}=C_{L} \frac{\rho_{a} v_{a}^{2}}{2} A_{F}
$$

where, $C_{L}$ is the lift coefficient.

For small angles, a symmetrical airfoil will generate a lift force roughly proportional to the angle of attack ${ }^{[27]}$. The equation $C_{L}=2 \pi \sin (\alpha+\beta)$ can be used to calculate $C_{L}$ at a low attack angle. Increasing the angle of attack beyond its critical value causes the airfoil to generate less $\operatorname{lift}^{[27]}$, then the equation $C_{L}=\sin 2(\alpha+\beta)$ should be used to calculate $C_{L}$ for this case ${ }^{[28]}$. Combined with the measured and calculated data, $C_{L}=2 \pi \sin (\alpha+\beta)$ at $(\alpha+\beta) \leq 30^{\circ}$ and $C_{L}=\sin 2(\alpha+\beta)$ at $(\alpha+\beta)>30^{\circ}$.

Hence, the lift force acting on the leaf is given by

$$
F_{L}=\left\{\begin{array}{cc}
3.18 v_{a}^{2} a b \sin \left(\alpha^{2}+\beta\right) & (\alpha+\beta) \leq 30^{\circ} \\
1.01 v_{a}^{2} a b \sin \left(\alpha^{2}+\beta\right) \cos (\alpha+\beta) & (\alpha+\beta)>30^{\circ}
\end{array}\right.
$$

Nonperiodic excitations are often referred to as transient, although some of them can last a long time ${ }^{[29]}$. Due to the working mechanism of the fan and leaf-airflow interaction, the airflow generated by the axial fan is treated as a nonperiodic excitation. When a leaf is subjected to nonperiodic excitation, it is forced to nonperiodically vibrate at the same frequency as the nonperiodic excitation. Considering the drag force and lift force on the leaf to be a series of impulses $f(\tau) \mathrm{d} \tau$, and a model of the leaf aerodynamic response can be developed using the convolution integral. If the impulsive force of $f(\tau)$ with a time duration of $\mathrm{d} \tau$ and unit impulse is $h(t-\tau)$, hence, the excitation corresponding to $f(\tau) \mathrm{d} \tau$ takes the form $f(t) h(t-\tau) \mathrm{d} \tau$. The exact response is obtained via integration:

$$
x(t)=\int_{0}^{t} f(\tau) h(t-\tau) \mathrm{d} \tau=\frac{1}{m \omega_{d}} \int_{0}^{t} f(\tau) e^{-\zeta \omega_{n}(t-\tau)} \sin \omega_{d}(t-\tau) \mathrm{d} \tau
$$

This integral is called the convolution integral ${ }^{[29]}$. The leaf response to the airflow was calculated via integration; hence, the displacement equation becomes

$$
\begin{aligned}
x(t) & =\int_{0}^{t} f(\tau) h(t-\tau) \mathrm{d} \tau=\frac{F_{0}}{m \omega_{d}} \int_{0}^{t} e^{-\zeta \omega_{n} t} \sin \omega_{d}(t-\tau) \mathrm{d} \tau \\
& =\frac{F_{0}}{k}\left[1-\frac{1}{\sqrt{1-\zeta^{2}}} e^{-\zeta \omega_{n} t} \cos \left(\omega_{d} t-\varphi\right)\right]
\end{aligned}
$$

Using the dot notation for the derivative, the leaf aerodynamic response velocity becomes

$$
{ }_{n} \frac{e^{-\zeta \omega_{n} t}}{\sqrt{1-\zeta^{2}}}\left[\zeta \omega_{n} \cos \left(\omega_{d} t-\varphi\right)+\omega_{d} \sin \left(\omega_{d}-\varphi\right)\right]
$$

where, $\varphi$ is the phase difference $\left(\varphi=\arctan \frac{\zeta}{\sqrt{1-\zeta^{2}}}\right), \omega_{d}$ is the $\mathrm{z}$ damped natural frequency $\left(\omega_{d}=\omega_{n} \sqrt{1-\zeta^{2}}\right.$ ), and $\omega_{n}$ is the undamped natural frequency $\left(\omega_{n}=\sqrt{\frac{k}{m}}\right)$.

According to the amplitude-frequency response characteristic curve, the amplitude and frequency of the exciting force can be obtained:

$$
\left\{\begin{array}{l}
A=\frac{A_{0}}{2 \zeta \sqrt{1-\zeta^{2}}} \\
\Omega=\omega_{n} \sqrt{1-2 \zeta^{2}}
\end{array}\right.
$$

The damping factor and natural frequency were obtained using the above two equations by measuring the curve for citrus and litchi leaf in response to airflow. The natural frequency is $6.28 \mathrm{rad} / \mathrm{s}$, and the relative damping factor $\zeta$ is 0.16 . The average quantity of citrus and litchi leaf is $0.5 \mathrm{~g}$ and $0.8 \mathrm{~g}$ in this experiment. Substituting these results into $\varphi=\arctan \frac{\zeta}{\sqrt{1-\zeta^{2}}}$ and $\omega_{d}=\omega_{n} \sqrt{1-\zeta^{2}}$, the phase difference $\varphi$ is $0.16 \mathrm{rad}$, the natural frequency $\omega_{d}$ is $6.20 \mathrm{rad} / \mathrm{s}$, the system stiffnesses of citrus and litchi leaves are $0.02 \mathrm{~N} / \mathrm{m}$ and $0.03 \mathrm{~N} / \mathrm{m}$, respectively, and the target leaf response time in the airflow is around $2 \mathrm{~s}$.

Substituting these results into Equations (7) and (8), the equations can be rearranged to obtain

$$
{ }^{\cdots} \frac{F_{0}}{n}
$$

Substituting Equations (3) and (5) into Equation (10), the following can be obtained:

Leaf aerodynamic response velocity in the direction of airflow:

$$
\frac{\cdots v_{a}^{2} \cdot a b \sin (\alpha+\beta)}{k}
$$

Leaf aerodynamic response in the perpendicular direction:

$$
\begin{array}{cc}
\frac{0.99 v_{a}^{2} \cdot a b \sin \left(\alpha^{2}+\beta\right)}{k} & (\alpha+\beta) \leq 30^{\circ} \\
\frac{v .31 v_{a}^{2} \cdot a b \sin \left(\alpha^{2}+\beta\right) \cos (\alpha+\beta)}{k} & (\alpha+\beta) \leq 30^{\circ}
\end{array}
$$

\subsection{Experiment material}

The spray test platform consists mainly of a wind delivery system and a spray system, as shown in Figure 2. The air delivery system mainly adjusts the wind velocity of the fan (SFWL3-2 axial fan, Hangzhou Chino Electromechanical Equipment Co., Ltd) through the frequency converter. The spray system includes mainly a plunger pump (Dp-160 ultrahigh pressure diaphragm pump, Pearl River Pump industry), electromagnetic valve (ZS1DF13N1D16, Hangzhou Meacon Co., Ltd), nozzle and intelligent flow monitoring system (5600, Hangzhou Meacon Co., Ltd). The cone nozzles were manufactured by American HYPRO Co., Ltd., and the spray angle is $110^{\circ}$. To minimize the effect of the external environment, the experiment was performed indoors, and a small canopy tree was selected as the target tree. The leaves of living citrus and litchi plants under natural growth were selected as the target. The selected inclination angle was $0^{\circ}-90^{\circ}$, and this angle range covers most inclination conditions in the natural state of the leaves. The roughness ratio is used to describe the roughness 
of the leaves, and the contact angle represents the performance of the interaction between the droplet and the wettability of the leaf surface. The Rtec Instrumentation 3D Profilometer was used to measure 3D surface structure of target leaves and calculate the roughness ratio. The contact profile of the droplet was determined from images captured using an OCA40 Micro Contact Angle Meter, and the contact angle was measured with a protractor. All the measures were repeated five times to calculate the averages. The geometric and surface texture parameters of the citrus and litchi target leaves are reported in Table 1.

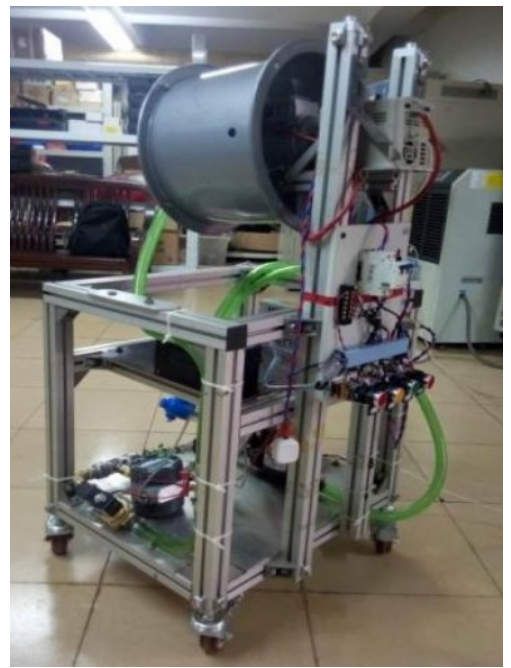

Figure 2 Spray test platform

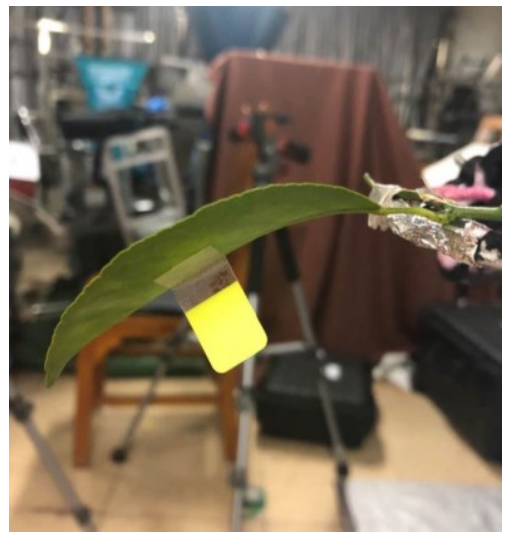

Figure 3 Fluorescent card on the target leaf

Table 1 Target leaf geometry parameters

\begin{tabular}{llcc}
\hline \multirow{2}{*}{ Parameter } & \multicolumn{2}{c}{ Target leaf } \\
\cline { 3 - 4 } & & Citrus & Litchi \\
\hline \multirow{3}{*}{ Geometry } & Area $/ \mathrm{mm}^{2}$ & $72 \times 42$ & $100 \times 42$ \\
& Thickness $/ \mathrm{mm}$ & 2307.9 & 3140.0 \\
& Petiole length $/ \mathrm{mm}$ & 0.23 & 0.16 \\
\hline \multirow{2}{*}{ Surface } & Roughness ratio & 0.7 & 0.9 \\
& Static contact angle $/\left({ }^{\circ}\right)$ & $70.4 \pm 2.7$ & $1.13 \pm 0.06$ \\
\hline
\end{tabular}

To better analyze the leaf motion state and ensure measurement accuracy, the fluorescent paper was attached as the fluorescent target in the middle of the leaf. As shown in Figure 3, the fluorescent target was used mainly to measure the aerodynamic response velocity and vibration angle of the leaf in the later stage. To analyze the droplet deposition on the leaf surface, Ponceaus $2 \mathrm{R}$ Biological Dye, which has a clear color, was used as the spray liquid to determine the deposition state and the flow trace, and the ratio of the Ponceaus $2 \mathrm{R}$ reagent to purified water was 1:600. The surface tension of this Ponceaus $2 \mathrm{R}$ solution can be measured via the pendant drop method in the laboratory ${ }^{[30]}$. The results indicate that the surface tension of the Ponceaus $2 \mathrm{R}$ solution $(0.071 \mathrm{~m} / \mathrm{s})$ is equal to the surface tension of water $(0.072 \mathrm{~m} / \mathrm{s})$.

\subsection{Experimental method}

2.3.1 Spray deposition characteristics test

To reduce the influence of pressure fluctuations of the test platform, the test was performed under constant temperature $\left(28^{\circ} \mathrm{C}\right)$ and a spray pressure of 0.9 Bar. The fan frequency converter was adjusted to obtain different outlet airflow velocities. Referring to the orchard spray operation parameter of the actual field spray, it was determined that the air delivery velocity ranged from $7.8 \mathrm{~m} / \mathrm{s}$ to $11.5 \mathrm{~m} / \mathrm{s}$, and the spray distance ranged from $0.4 \mathrm{~m}$ to $2.0 \mathrm{~m}$ (the corresponding leaf aerodynamic response velocity was in the range from $0.05 \mathrm{~m} / \mathrm{s}$ to $0.25 \mathrm{~m} / \mathrm{s}$ ), and the spray test platform travel velocity was set to $0.2 \mathrm{~m} / \mathrm{s}$. The branches of the orchard were fixed using a clamping bracket, and the initial inclination angle of the leaf was determined using a protractor. The variables and parameters were tested using the high-speed camera at the beginning of each working condition are reported in Table 2 . The test index is the aerodynamic response velocity of the leaf, and the test treatment was repeated three times to obtain the average value as the result.

Table 2 Test parameters

\begin{tabular}{lc}
\hline \multicolumn{1}{c}{ Parameter } & Value \\
\hline Target leaf & Citrus, Litchi \\
Leaf inclination angle $/\left(^{\circ}\right)$ & $0^{\circ}, 30^{\circ}, 60^{\circ}, 90^{\circ}$ \\
Leaf aerodynamic response velocity $/ \mathrm{m} \cdot \mathrm{s}^{-1}$ & $0.05-0.25$ \\
Spray distance $/ \mathrm{m}$ & $0.4,1.0,1.6$ \\
\hline
\end{tabular}

Figure 4 shows the layout of the spray test. In each test case, the FASTCAM high-speed camera was used to separately record the vibration process of the leaf under airflow. To improve image clarity, the shooting frame rate of the high-speed camera was selected to be 125 frames/s.
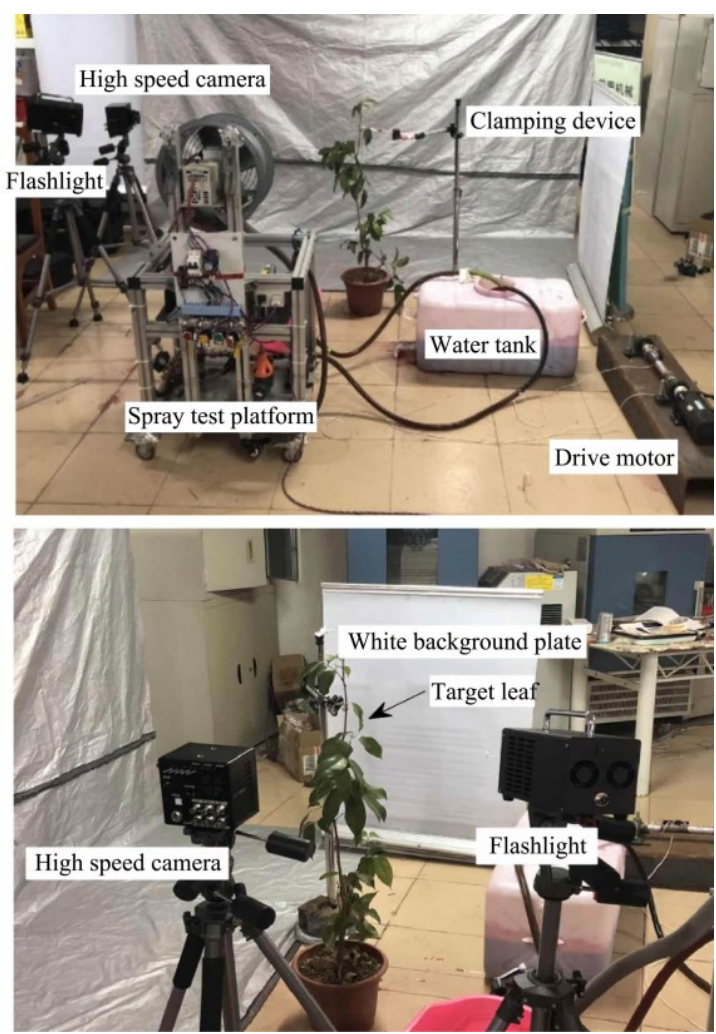

Figure 4 Schematic diagram of the spray experiment 
2.3.2 Leaf aerodynamic response velocity and angle measurement method

The Photron Fastcam Analysis software package was used to analyze the leaf vibration video captured by the high-speed camera, as shown in Figure 5. The scale and coordinate system were set, and the center of the fluorescent target was tracked as a dynamic tracking point. The vectors of leaf aerodynamic response velocity were observed and its root means square value can be calculated.

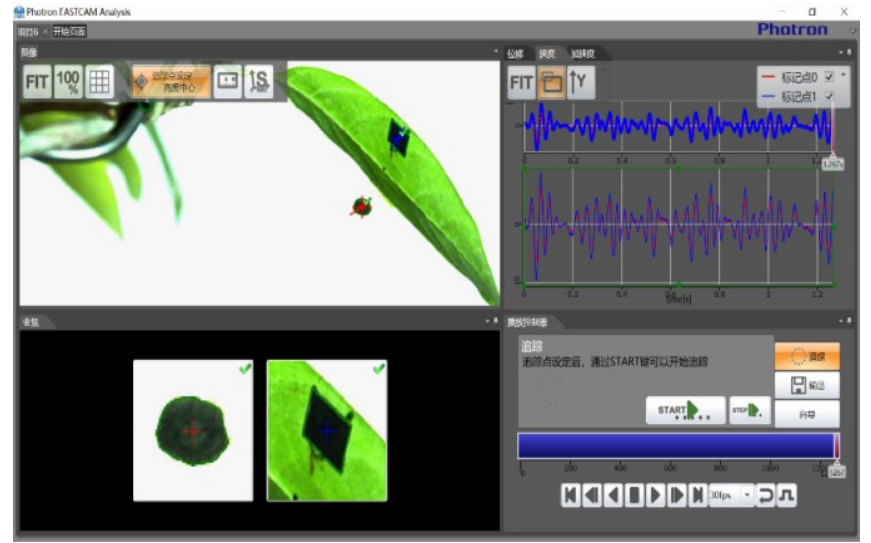

Figure 5 Leaf aerodynamic response velocity calculation

In this test, the vibration angle of the leaf under airflow was regarded as the vibration amplitude of the leaf. The image of the wind vibration video of the leaf was post-processed using Matlab, and the position coordinates of the center of gravity of the yellow fluorescent target and the position coordinates of the petiole were identified. The coordinates of the joint point could be calculated as the angle between the horizontal line and the horizontal angle of the leaf. The angle $\alpha$ of the leaf was calculated by searching for the tip position of the leaf, using the equation $A_{F}=A_{L} \cdot \sin \alpha$, this value was calculated for each instantaneous vibration angle. Figure 6 illustrates the definition of the instantaneous inclination of the leaf under wind vibration. Through the above two methods, the instantaneous vibration angle of the leaf under airflow and its corresponding current projection area could be calculated to explore the changes in the vibration state of the leaf under airflow.

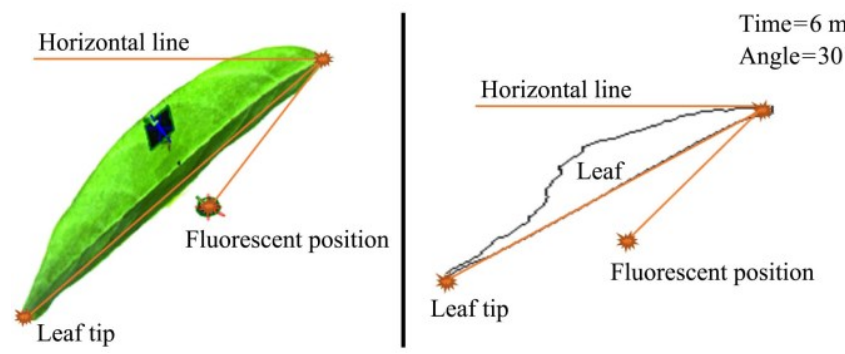

Figure 6 Schematic diagram of the vibration angle of the leaf

\subsubsection{Spray deposition characteristics test}

The deposition characteristics of droplets on the leaf were tested using the same test parameters and methods as the aerodynamic response characteristics of the leaf. At the beginning of the test, the test platform air delivery system and the spray system were turned on for approximately $10 \mathrm{~s}$ to reach a stable state. The test platform moved at a speed of $0.2 \mathrm{~m} / \mathrm{s}$ and the camera was used to photograph the target leaf surface. At the end of each working condition test, the sample images were classified and saved. The droplet coverage ratio (The proportion of droplets on the leaf, that is, the area of the leaf divided by the total area of droplets) was calculated using the Matlab image toolbox. After each test treatment, the absorbent paper was used to gently blot the droplets on the leaf surface, and then the next test treatment was performed. The test layout is also shown in Figure 5 and the test parameters are reported in Table 2. The measured test indexes are the aerodynamic response velocity of the leaf and the droplet coverage ratio on the leaf surface. The test conditions were repeated three times to obtain an average value.

\subsubsection{Calculation of droplet coverage ratio}

The droplet retention flow on the leaf surface is defined as the spray volume deposited on the leaf surface, and the droplet coverage ratio can be used to characterize the droplet retention flow on the leaf surface. The Matlab software was used to calculate the coverage ratio of the droplet, as shown in Figure 7. By comparing the droplet coverage ratio of the images with the results of the water-sensitive test papers, the accuracy of the measurement is found to satisfy the requirements of this study, and thus this image processing method can be used to calculate the target leaf droplet coverage ratio and the size of the deposited droplets.

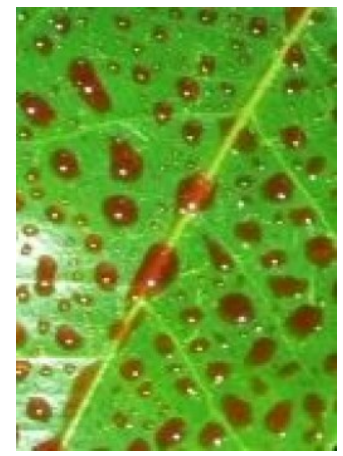

a. Original image

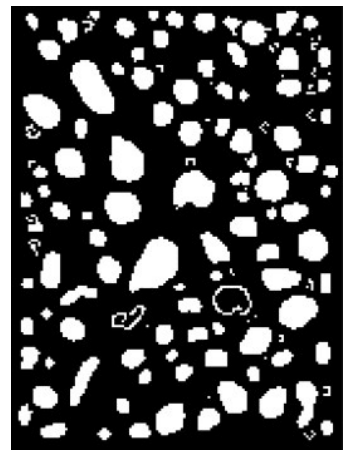

c. Filling holes

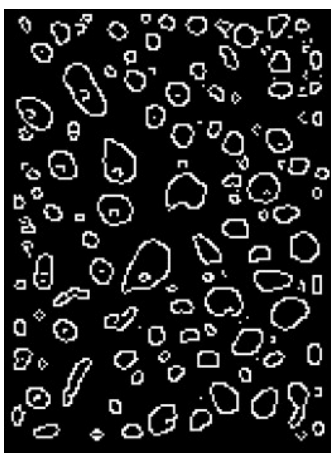

b. Edge detection

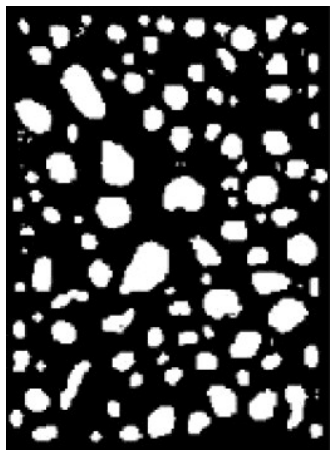

d. Final image
Figure 7 Calculation of leaf droplet coverage ratio and droplet distribution

\subsubsection{Definition of leaf vibration amplitude}

The leaf excited by airflow will generate vibration disturbances During this test, the leaf amplitude was used to measure its vibration amplitude to explore the law of leaf vibration. The definition of the leaf angle is shown in Figure 8.

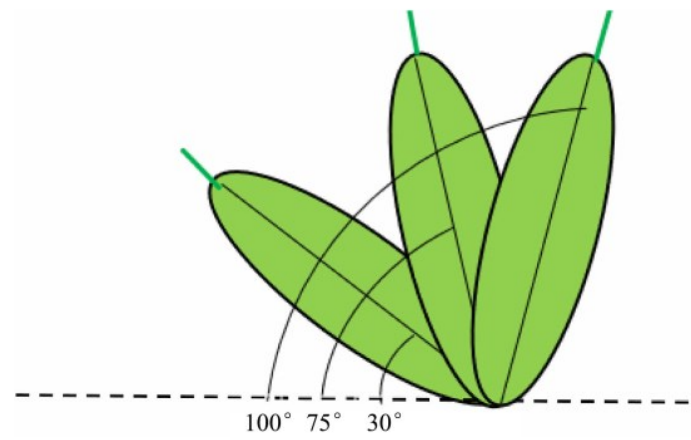

Figure 8 Schematic diagram illustrating the definition of the leaf inclination angle 


\section{Results and discussion}

\subsection{Leaf aerodynamic response}

\subsubsection{Aerodynamic response velocity in the airflow direction}

The measured and calculated values of aerodynamic response velocity in the airflow direction for the target leaf are shown in Figure 9 and Figure 10. The measured root mean square (RMS) value of the aerodynamic response velocity and the calculated value of the model in Equation (11) were relatively consistent.

First, the effect of the airflow velocity on the leaf aerodynamic response velocity in the airflow direction was analyzed. From Equation (11), it can be known that the leaf aerodynamic response velocity in the airflow direction is proportional to the airflow velocity in the airflow direction squared. As shown in Figure 9, when a lower outlet airflow velocity (less than $11.5 \mathrm{~m} / \mathrm{s}$ in this experiment) acts on a leaf with a given initial inclination angle, the aerodynamic response velocity in the airflow direction has a linear relationship with the outlet airflow velocity.

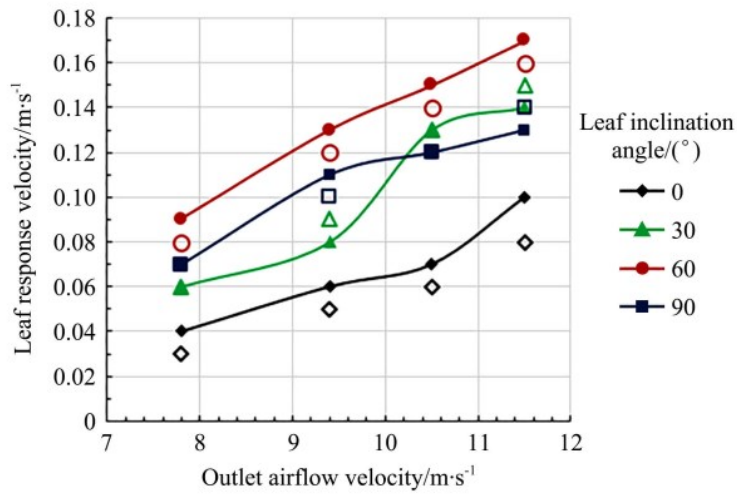

a. Citrus

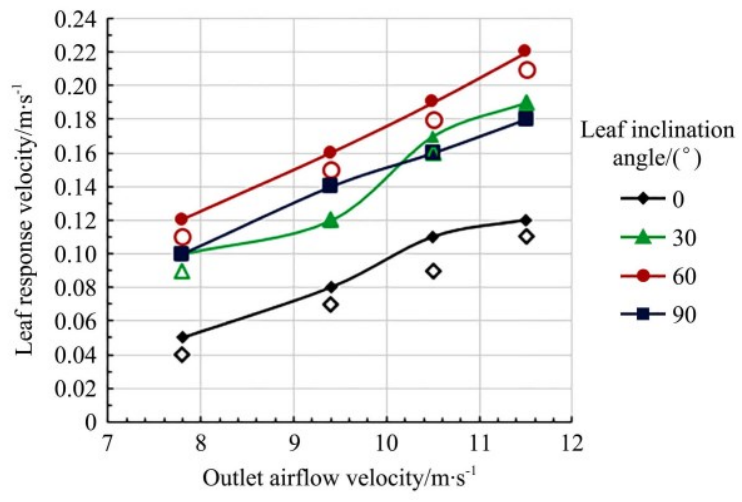

b. Litchi

Figure 9 Measured (curve) and calculated values (open marker) of the leaf aerodynamic response velocity in main direction of airflow

The effect of the leaf initial inclination angle on the aerodynamic response velocity in the airflow direction is shown in Figure 10. At the same airflow velocity, the aerodynamic response velocity in the airflow direction first increased and then decreased with increasing leaf initial inclination angle. At the rated outlet airflow velocity, if the leaf inclination angle was $0^{\circ} \leq(\alpha+\beta)<90^{\circ}$, then the leaf aerodynamic response velocity in the airflow direction was proportional to the initial inclination angle $\alpha$ of the target leaf. The initial angles of $0^{\circ}, 30^{\circ}$, and $60^{\circ}$ of the target leaf had this relationship with the leaf aerodynamic response velocity as shown. If the target leaf inclination angle was $90^{\circ} \leq(\alpha+\beta)<180^{\circ}$, then the leaf aerodynamic response velocity squared in the airflow direction was inversely proportional to the initial inclination $\alpha$ of the target leaf. The initial inclination angle of the target leaf of $90^{\circ}$ had this relationship with the aerodynamic response velocity as shown. If the target leaf initial inclination angle was $(\alpha+\beta)=90^{\circ}$, then the corresponding leaf aerodynamic response velocity in the airflow direction was maximized.

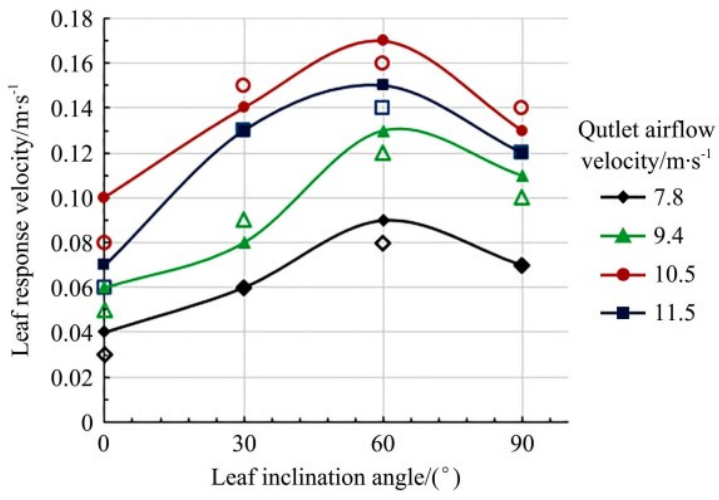
a. Citrus

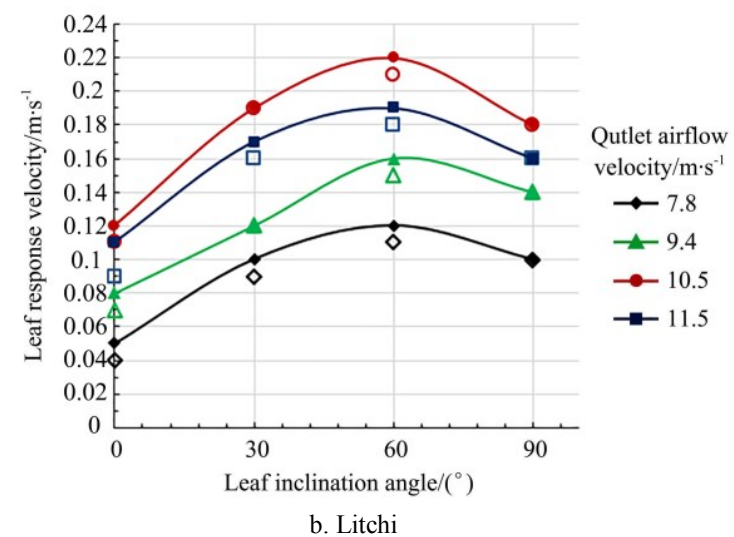

Figure 10 Measured (curve) and calculated values (open marker) of the leaf aerodynamic response velocity in main direction of airflow

For different target leaves, if the airflow velocity at the target leaf $v_{a}$ and the leaf initial inclination $\alpha$ was constant, then the leaf aerodynamic response velocity in the airflow direction was associated with the leaf size $(a, b)$ and the system stiffness $K$ of the leaf response system. Although the stiffness in the leaf aerodynamic response system for citrus leaves was slightly less than that for litchi leaves, the litchi leaf was larger than the citrus leaf. Therefore, the leaf aerodynamic response velocity in the airflow direction for the litchi leaf was slightly greater than that of the citrus leaf as shown in Figure 9 and Figure 10.

3.1.2 Aerodynamic response velocity in the perpendicular direction

The measured and calculated values of the aerodynamic response velocity in the perpendicular direction for the target leaf are shown in Figure 11 and Figure 12. The measured value of the leaf aerodynamic response velocity squared and the calculated value of the model in Equation (12) also were relatively consistent.

The airflow velocity had an effect on the leaf aerodynamic response velocity in the perpendicular direction. According to Equation (12), the leaf aerodynamic response velocity in the perpendicular direction was proportional to the airflow velocity squared at the target leaf. As shown in Figure 10, when a lower outlet airflow velocity (less than $1.5 \mathrm{~m} / \mathrm{s}$ in this experiment) acts on the target leaf, the leaf aerodynamic response velocity in the perpendicular direction has a linear relationship with the outlet airflow velocity. If the initial inclination angle of the leaf was $0^{\circ}$ 
or $30^{\circ}$, the leaf aerodynamic response velocity in the perpendicular direction was proportional to the outlet airflow velocity. However, if the initial inclination angle of the leaf was $60^{\circ}$ or $90^{\circ}$, the leaf aerodynamic response velocity in the perpendicular direction was inversely proportional to the outlet airflow velocity.

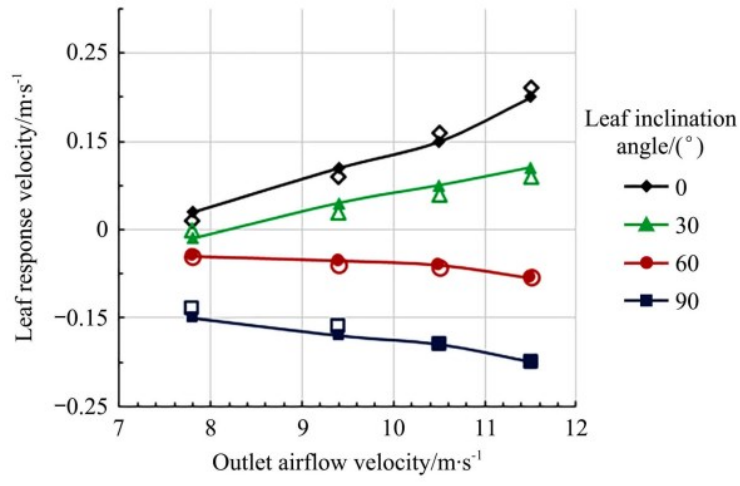

a. Citrus

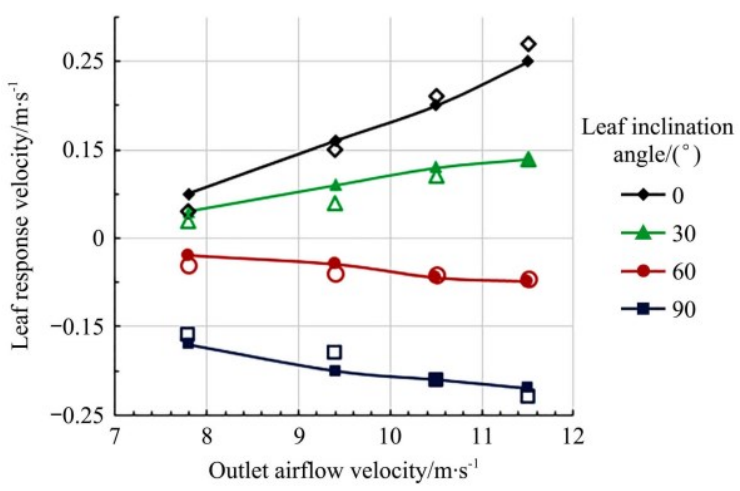

b. Litchi

Figure 11 Measured (curve) and calculated (open marker) leaf aerodynamic response velocity in the perpendicular of airflow

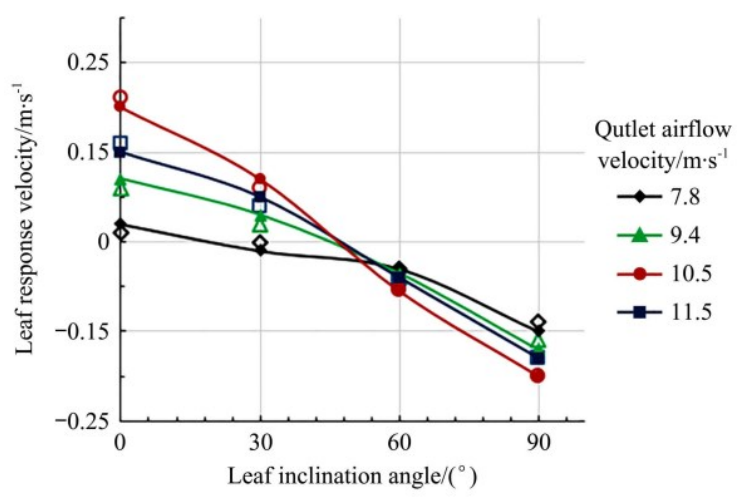

a. Citrus leaf

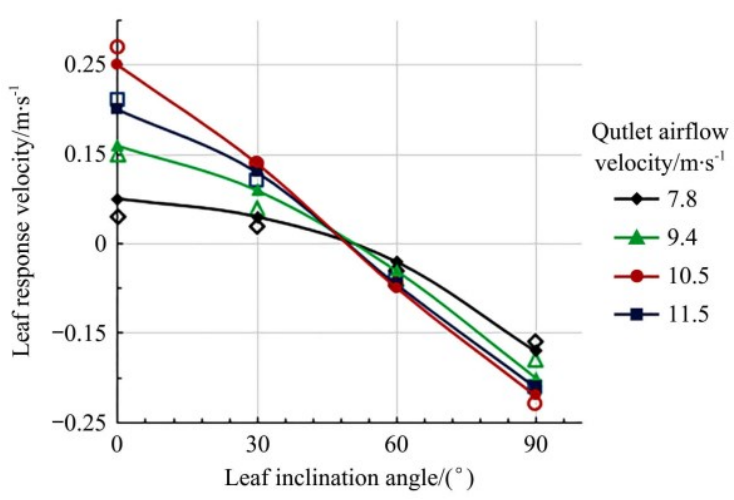

b. Litchi leaf

Figure 12 Measured (curve) and calculated (open marker) leaf aerodynamic response velocity in the perpendicular of airflow
The leaf inclination angle also had an effect on the leaf aerodynamic velocity. As shown in Figure 12, as the leaf initial inclination angle increased, at the same airflow velocity, the leaf aerodynamic response velocity in the perpendicular direction first decreased to 0 and then increased. At the rated outlet airflow velocity, together with Equation 12, if the inclination angle of the target leaf was $0^{\circ} \leq(\alpha+\beta)<30^{\circ}$, then the leaf aerodynamic response velocity in the perpendicular direction was proportional to the leaf inclination angle $(\alpha+\beta)$. At a lower outlet airflow velocity, the leaf inclination angle of $0^{\circ}$ had this relationship with the leaf aerodynamic response velocity, as shown in Figure 12. If the inclination angle of the target leaf was $30^{\circ} \leq(\alpha+\beta)<90^{\circ}$, then the leaf aerodynamic response velocity in the perpendicular direction had no relation to the inclination angle $(\alpha+\beta)$ of the target leaf. The initial inclination angle of the target leaf of $30^{\circ}$ had this relationship with the leaf aerodynamic response velocity as shown. If the target leaf inclination was $90^{\circ} \leq(\alpha+\beta)<180^{\circ}$, then the leaf aerodynamic response velocity in the perpendicular direction was inversely proportional to the target leaf inclination angle $(\alpha+\beta)$. The initial angle of the target leaf of $90^{\circ}$ had this relationship with the leaf aerodynamic response velocity as shown. For an initial inclination angle of the target leaf of $60^{\circ}$, if the airflow velocity at the target leaf was $v_{a}=3 \mathrm{~m} / \mathrm{s}$, then the calculated value of the leaf aerodynamic response velocity in the perpendicular direction was 0 because of $\cos (\alpha+\beta)=0$. In such a situation, the relation to the leaf aerodynamic response status was as follows: when the inclination angle of the target leaf was $90^{\circ}$, the vibration existed in the airflow direction only under the influence of the airflow.

Likewise, for different target leaves, if the airflow velocity $v_{a}$ and the initial inclination angle $\alpha$ were related, the leaf aerodynamic response in the perpendicular direction was basically related to the leaf size $(a, b)$ and the stiffness $k$ in the pneumatic response system. The stiffness $k$ of citrus leaves was slightly less than that of litchi leaves in the aerodynamic response system. However, the size of litchi leaves is greater than that of citrus leaves. Therefore, the leaf aerodynamic response velocity in the perpendicular direction for the litchi leaf was slightly greater than that for the citrus leaf.

3.1.3 Influence of excitation airflow velocity on the vibration angle of the leaf

Figure 13 shows the box diagram of the target leaf (citrus and litchi) with an initial inclination of $30^{\circ}$ under airflow changes. The box diagram consists of a box and two upper and lower vertical lines, where the box represents the data concentration range, the red line is the median of the angle of the leaf, and the upper and lower vertical lines indicate the extension of the data up and down. The symbol ' + ' indicates an outlier and represents the maximum value of the leaf angle. It can be observed from the figure that as the excitation airflow velocity increased, the leaf was vibrated under the airflow, the range of the vibration angle (leaf inclination during vibration) of the leaf gradually increased, and the mean and median of the leaf angle increased as well.

\subsection{Characteristics of spray droplet deposition}

The multivariate analysis of variance showed that interaction among leaf initial inclination, outlet airflow velocity and spray distance has significant influence on the deposition characteristics of droplets. In order to explain how the multivariate interaction affects the deposition of droplets on the leaf, the leaf aerodynamic response velocity is introduced to explain mechanism of droplet deposition. 


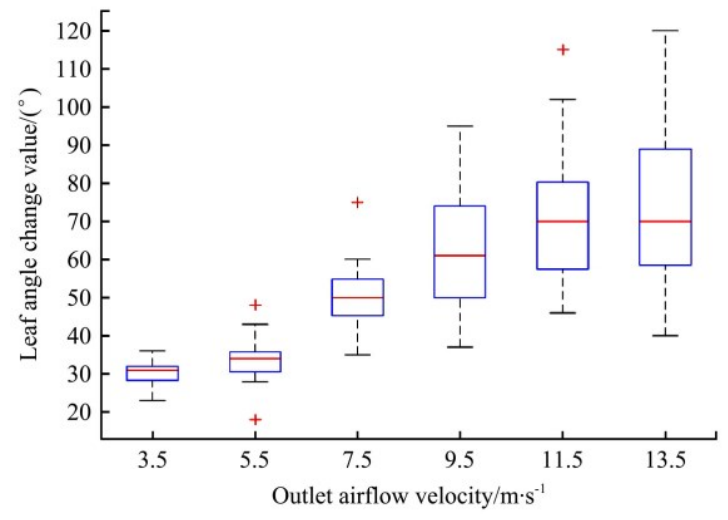

a. Citrus

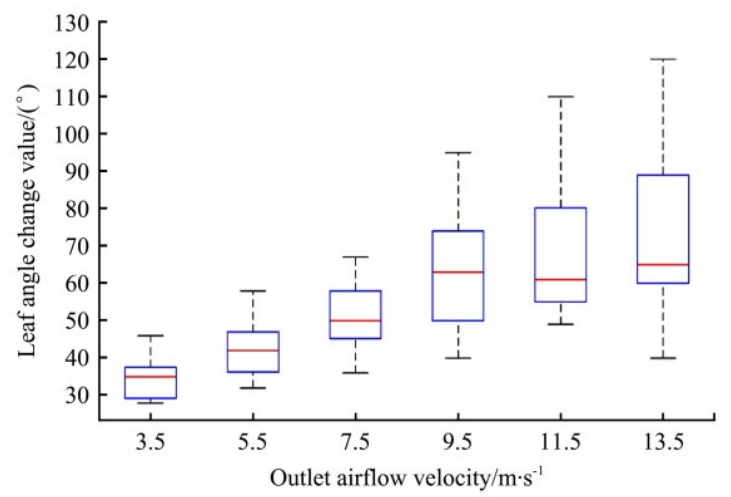

b. Litchi

Figure 13 Leaf angle change value under outlet airflow

The interaction between dynamic target leaves and droplets has an effect on the droplet deposition on the leaf surface. By understanding the influence of dynamic leaves on droplet deposition, the mechanism of the influence of various spraying parameters on the droplets is explored. Taking the droplet data of citrus target leaves as an illustrative example, as shown in Figure 14 , the scatterplot and fitting curve of the droplet coverage on the target leaf surface under different leaf aerodynamic response velocities were analyzed by fitting the graph to determine the change rules. Regarding the scatterplot analysis, as the aerodynamic response velocity of the leaf increased, the overall trend of droplet coverage ratio decreased. The high-velocity airflow mixed with the droplets acted on the target leaf surface, due to the energy of the drip group was large, the droplet was more likely to bounce and splash when colliding with the target leaf surface. At the same time, the target leaf vibrated under the action of the airflow, and the aerodynamic response velocity of the leaf

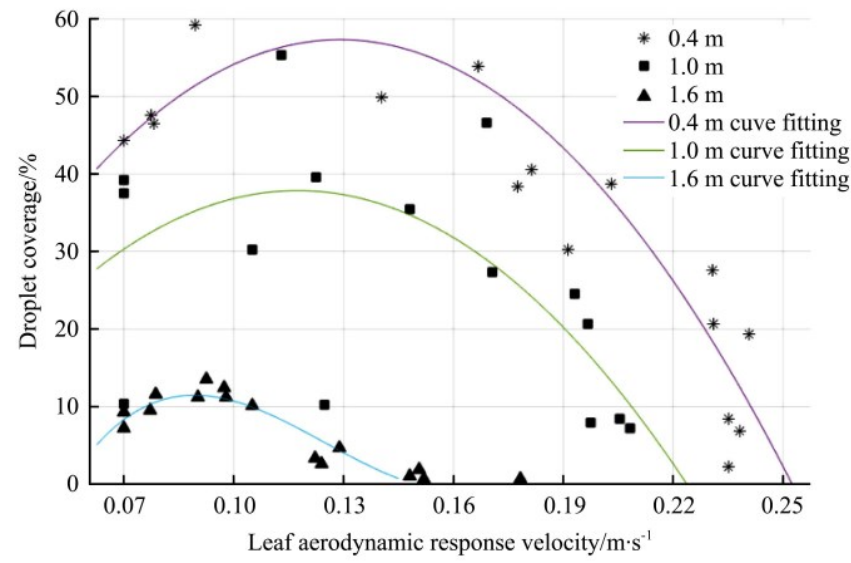

Figure 14 Effects of the leaf aerodynamic response on droplet coverage increased as the airflow velocity increased. The droplets that adhered to the target leaf surface were subject to the action of the airflow. Therefore, the droplets were more likely to lose from the target leaf surface. An increase in leaf aerodynamic response velocity will result in a decrease in droplet coverage on the leaf surface. When the spray distance are $0.4 \mathrm{~m}, 1.0 \mathrm{~m}$ and $1.6 \mathrm{~m}$, leaf aerodynamic response velocity $0.13 \mathrm{~m} / \mathrm{s}, 0.11 \mathrm{~m} / \mathrm{s}$ and $0.08 \mathrm{~m} / \mathrm{s}$ corresponds to the maximum droplet coverage ratios. According to the analysis, the aerodynamic response velocity of the leaf has a significant influence on the coverage of the droplets on the leaf surface. The aerodynamic response velocity and the coverage ratio of the droplets show certain regularity.

The interaction between dynamic target leaves and droplets has a significant effect on the droplet coverage on the leaf surface and based on the experimental results, the droplet deposition state on the target leaf surface is significantly different, mainly due to the interactions among the leaf, airflow and droplets. Figures 15 and 16 show the droplet distribution on the target leaf surface and the deposited droplets on the leaf surface. Four typical deposition states (uniform, aggregation, flow and loss) of droplets on the leaf surface were proposed. The choice of four leaf response velocities was based on the choice of four typical deposition states visually, and the leaf deposition states under four aerodynamic response velocities were more recognizable. When the aerodynamic response velocity of the leaf was $0.07 \mathrm{~m} / \mathrm{s}$, the size and arrangement of the droplets are uniformly distributed. The droplet particles deposited on the target leaf surface are relatively small, and the total deposition volume is large. As the aerodynamic response velocity of the leaf increases, the total deposition volume demonstrated a decreasing trend, but the sedimentary particle size of the deposited droplets gradually increased. When the aerodynamic response velocity of the leaf was $0.22 \mathrm{~m} / \mathrm{s}$, the droplets under high-velocity airflow had greater kinetic energy. More droplets will be lost and drifted when interacting with the vibrated leaves, resulting in that the deposited droplets on the target leaf surface were unevenly arranged and the particle size distribution was uneven, as shown in Figure 16d. Figure 16 also shows the four droplet deposition states on the target leaf surface. Figure 14 reveals that the highest droplet deposition ratio and best deposition state on the leaf surface occur when the leaf aerodynamic response velocity was less than $0.14 \mathrm{~m} / \mathrm{s}$. When the aerodynamic response velocities of the leaf were $0.17 \mathrm{~m} / \mathrm{s}$ and $0.22 \mathrm{~m} / \mathrm{s}$, as shown in Figures 16c and 16d, the distribution of the drops on the leaves was extremely uneven, which should be avoided in actual operations. In actual field activities, the volume

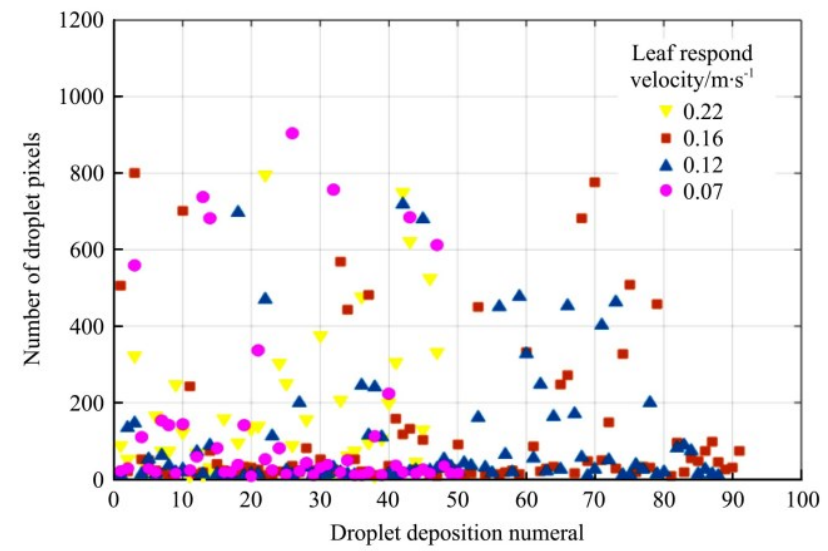

Figure 15 Aerodynamic response velocity of four-leaf responses to the particle size and quantity of submerged droplets 
of droplets deposited on the leaf surface should be optimized, and the droplets should be distributed evenly with minimum loss to achieve a good pest control effect, save resources and protect the environment.

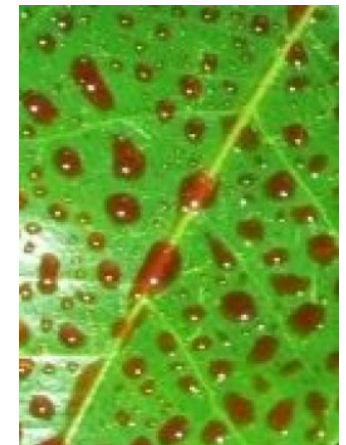

a. Droplet uniform distribution state (leaf response velocity $=0.07 \mathrm{~m} / \mathrm{s}$ )

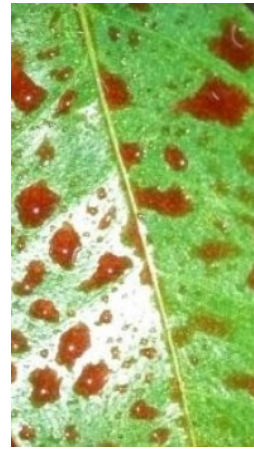

c.Droplet flow state (leaf response velocity $=0.16 \mathrm{~m} / \mathrm{s}$ )

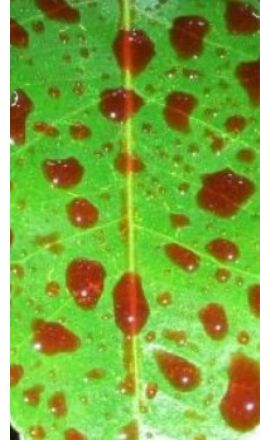

oplets aggregate distribution state (leaf response velocity $=0.12 \mathrm{~m} / \mathrm{s}$ )

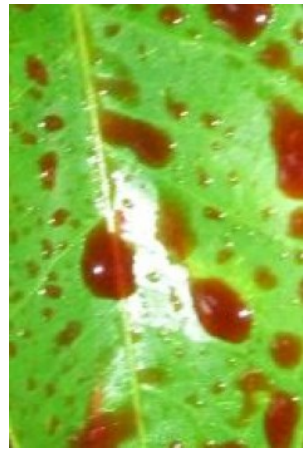

d. Droplet loss state (leaf response velocity $=0.22 \mathrm{~m} / \mathrm{s}$ )
Figure 16 Four droplets deposition states on the target leaf surface

\section{Conclusions}

In this study, spray tests of a target leaf were performed using different air spray parameters, the aerodynamic response velocity and droplet coverage ratio of the leaf were measured. The characteristics of aerodynamic response and droplet deposition of the leaf were analyzed.

The results indicated that the calculated root mean square of the leaf response velocity had good correspondence with the measured value. The amplitude range of the vibration angle of leaf increased as the air delivery velocity increased. At given conditions of spray liquid and leaf surface texture, the droplet coverage is strongly influenced by the leaf aerodynamic response velocity. The droplet coverage on the leaf surface increased and then decreased with the increase of leaf aerodynamic response velocity. According to the analysis of droplet deposition states, the uniformity of the droplet size and volume distribution of droplets on the leaf surface was related to the leaf aerodynamic response velocity, and the highest droplet deposition ratio and best deposition state on the leaf surface occur when the leaf aerodynamic response velocity was less than $0.14 \mathrm{~m} / \mathrm{s}$. This study can provide a theoretical basis for research on dynamic droplet deposition when sprayed by air-assisted sprayer.

\section{Acknowledgements}

This work was supported by earmarked funds for the Special project of Rural Vitalization Strategy of Guangdong Academy of Agricultural Sciences (Accession No. TS-1-4), the Guangdong Provincal Modern Agricultural Industry Technology System
(Accession No. 2019KJ123), the Key-Area Research and Development Program of Guangdong Province (Grant No. 2019B020223002), the China Agriculture Research System (CARS-32-14) and the National Key R\&D Program of China (Grant No. 2018YFD0201101).

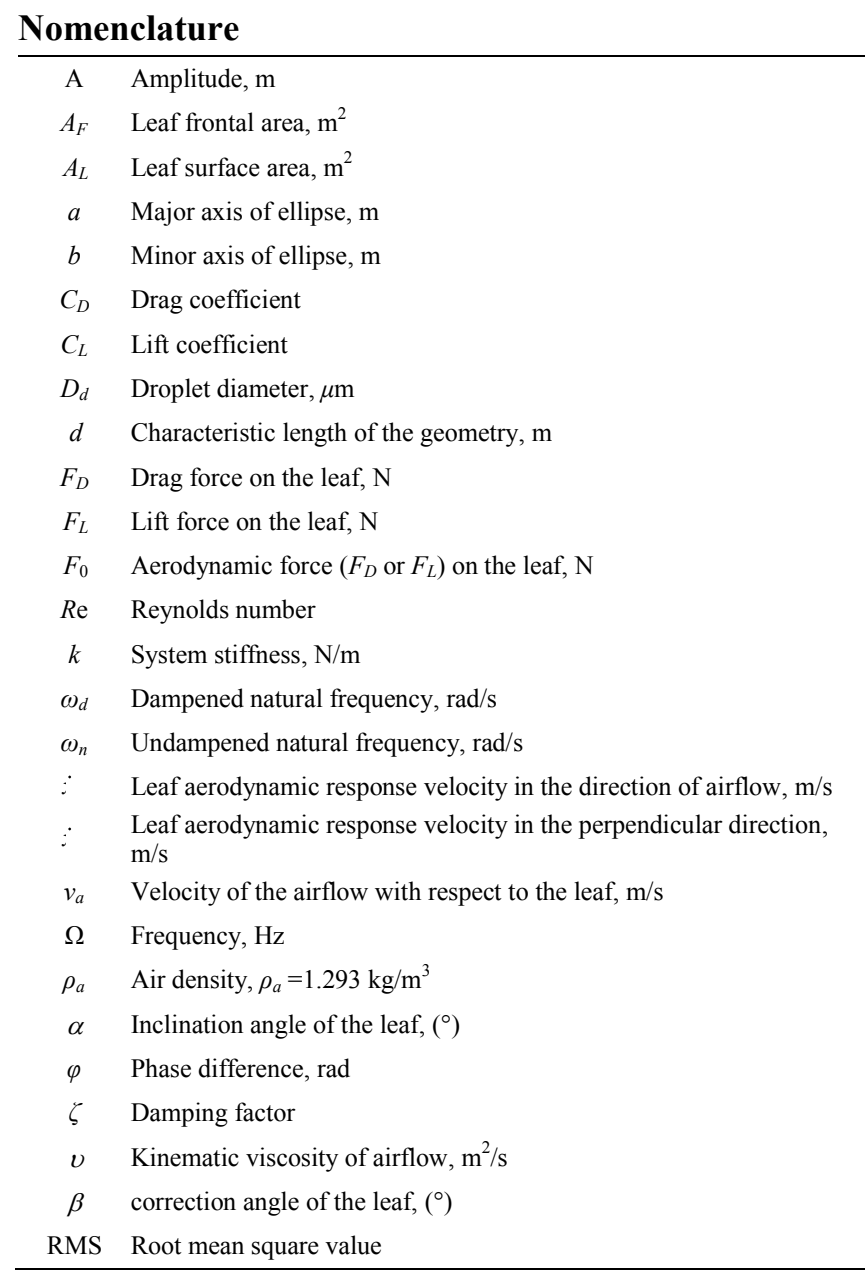

\section{[References]}

[1] Miranda-Fuentes A, Llorens J, Rodríguez-Lizana A, Cuenca A, Gil E, Blanco-Roldán G L, et al. Assessing the optimal liquid volume to be sprayed on isolated olive trees according to their canopy volumes. Science of the Total Environment, 2016; 568: 296-305.

[2] Li L L, He X K, Song J L, Liu Y, Wang Z C, Li J Y, et al. Comparative experiment on profile variable rate spray and conventional air assisted spray in orchards. Transactions of the CSAE, 2017; 33(16): 56-63. (in Chinese)

[3] Niu C Q, Zhang W J, Wang Q, Zhao X X, Fan G J, Jiang H H. Research status and trend of orchard air supply spray air volume regulation. Chinese Journal of Agricultural Mechanization, 2020; 41(12): 48-54.

[4] Grella M, Marucco P, Balafoutis A T, Balsari P. Spray drift generated in vineyard during under-row weed control and suckering: evaluation of direct and indirect drift-reducing techniques. Sustainability, 2020; 12(12): 5068. doi: 10.3390/su12125068.

[5] Larbi P A, Salyani M. Model to predict spray deposition in citrus airblast sprayer applications: Part 2. Spray deposition. Transactions of the ASABE, 2012; 55(1): 41-48.

[6] Dorr G J, Kempthorne D M, Mayo L C, Forster W A, Zabkiewicz J A, McCue S W, et al. Towards a model of spray-canopy interactions: Interception, shatter, bounce and retention of droplets on horizontal leaves. Ecological Modelling, 2014; 290: 94-101.

[7] Dorr G J, Wang S S, Mayo L C, McCue S W, Forster W A, Hanan J, et al Impaction of spray droplets on leaves: Influence of formulation and leaf character on shatter, bounce and adhesion. Experiments in Fluids, 2015; 56(7): 143. doi: 10.1007/s00348-015-2012-9. 
[8] Bueno M R, Cunha J P A R, de Santana D G. Assessment of spray drift from pesticide applications in soybean crops. Biosystems Engineering, 2017; 154: 35-45

[9] Qin W, Xue X, Zhang S, Wang B. Droplet deposition and efficiency of fungicides sprayed with small UAV against wheat powdery mildew. International Journal of Agricultural and Biological Engineering, 2018; 11(2): 27-32

[10] Gaskin R E, Steele K D, Forster W A. Characterising plant surfaces for spray adhesion and retention. Adjuvant Technology, 2005; 58: 179-183.

[11] Musiu E M, Qi L J, Wu Y L. Spray deposition and distribution on the targets and losses to the ground as affected by application volume rate, airflow rate and target position. Crop Protection, 2019; 116: 170-180.

[12] Grella M, Marucco P, Manzone M, Gallart M, Balsari P. Effect of sprayer settings on spray drift during pesticide application in poplar plantations. Science of the Total Environment, 2016; 578: 427-439.

[13] Taylor W A, Shaw G B. The effect of drop speed, size and surfactant on the deposition of spray on barley and radish or mustard. Pesticide Science, 1983; 14(6): 659-665.

[14] Whitney J D, Salyani M, Churchill D B, Knapp J L, Whiteside J O, Littell R C. A field investigation to examine the effects of sprayer type, ground speed, and volume rate on spray deposition in Florida citrus. Journal of Agricultural Engineering Research, 1989; 42(4): 275-283.

[15] Xu L Y, Zhu H P, Ozkan H E, Thistle H W. Evaporation rate and development of wetted area of water droplets with and without surfactant at different locations on waxy leaf surfaces. Biosystems Engineering, 2010; 106(1): 58-67.

[16] Machado W A, Silva S M, Carvalho S M, Cunha J. Effect of nozzles, application rates, and adjuvants on spray deposition in wheat crops. Engenharia Agrícola, 2019; 39(1): 83-88.

[17] Salcedo R, Zhu H P, Zhang Z H, Wei Z M, Chen L M, Ozkan E, et al. Foliar deposition and coverage on young apple trees with PWM-controlled spray systems. Computers and Electronics in Agriculture, 2020; 178: 105794. doi: 10.1016/j.compag.2020.105794.
[18] Li J, Cui H J, Ma Y K, Xun L, Li Z Q, Yang Z, Lu H Z. Orchard spray study: A pediction model of droplet deposition states on leaf surfaces. Agronomy, 2020; 10(5): 747. doi: 10.3390/agronomy10050747.

[19] Yuan H Z, Qi S H, Yang D B. Study on the point of run-off and the maximum retention of spray liquid on crop leaves. Chinese Journal of Pesticide Science, 2000; 2(4): 66-71. (in Chinese)

[20] Wolf R E. Drift-reducing strategies and practices for ground applications. Technology \& Health Care Official Journal of the European Society for Engineering \& Medicine, 2013; 19(1): 1-20.

[21] Shao C P, Chen Y J, Lin J Z. Wind induced deformation and vibration of a Platanus acerifolia leaf. Acta Mechanica Sinica, 2012; 28(3): 583-594.

[22] Steven V. Drag and reconfiguration of broad leaves in high winds. Journal of Experimental Botany, 1989; 40(8): 941-948.

[23] Monteith J L. The radiation regime and architecture of plant stands. Journal of Ecology, 1981; 71(1): 344-345.

[24] Warneke B W, Zhu H P, Pscheidt J W, Nackley L L. Canopy spray application technology in specialty crops: A slowly evolving landscape. Pest Management Science, 2020; ps.6167. doi: 10.1002/ps.6167.

[25] Cengel Y, Cimbala J. Fluid mechanics: Fundamentals and applications. New York: McGraw-Hill Higher Education, 2013; 1024p.

[26] Stanford A L, Tanner J M. Mechanics of fluids. Physics for Students of Science and Engineering, 1985; 79(4): 234-264.

[27] Klaus W. A comparison of explanations of the aerodynamic lifting force. American Journal of Physics, 1987; 55(1): 50-54.

[28] Jiang H B, Cao S L, Cheng Z Q. Lift and drag coefficients of flow around a flat plate at high attack angles. Chinese Journal of Applied Mechanics, 2011; 28: 518-520. (in Chinese)

[29] William T T, Dillon D M. Theory of vibration with applications. New York: Taylor \& Francis, 1998; 534p.

[30] Berry J D, Nesson M J, Dagastine R R, Chan D Y C, Tabor R F Measurement of surface and interfacial tension using pendant drop tensiometry. Journal of Colloid and Interface Science, 2015; 45: 226-237. 